\title{
Resource Allocation Scheme to Support QoS in Mobile Multimedia Networks
}

\author{
Gi-Sung Lee ${ }^{1}$ and Jong-Chan Lee ${ }^{2^{*}}$ \\ ${ }^{1}$ Division of Computer \& Game, Howon University, South Korea \\ ${ }^{2}$ Department of Computer Information Engineering, Kunsan National University, \\ South Korea \\ Iygslee@howon.ac.kr, ${ }^{2}$ chan2000@kunsan.ac.kr
}

\begin{abstract}
The macrocell-femtocell overlaid system is a promising means by which to extend coverage and to support higher data rates for mobile multimedia services. This paper proposes a resource allocation mechanism to enhance service continuity in a Long Term Evolution Advanced system. In order to support service continuity in real-time services, it performs load control to satisfy maximal data throughput. Moreover, it considers the QoS requirements of real-time and non-real-time services, such as voice, video streaming, and data. Simulation results show that our scheme provides better performance than a conventional one with respect to outage probability and data transmission throughput.
\end{abstract}

Keywords: QoS, Service Continuity, Real-time Services, Macrocell, Femtocell

\section{Introduction}

The macrocell-femtocell overlaid Long Term Evolution Advanced (LTE Advanced) network calls for the development of new frameworks and approaches to meet the specific challenge of supporting adaptive QoS in a controlled manner, although it considers the frequent and random mobility of the mobile terminal (MT) and the dynamically changing network resource availability [1-2]. Figure 1 shows the concept of femtocell networks overlaid within the macrocell network considered in this research. Multimedia services on the Internet differ from each other with respect to their resource requirements, performance objectives, and resource usage efficiencies.

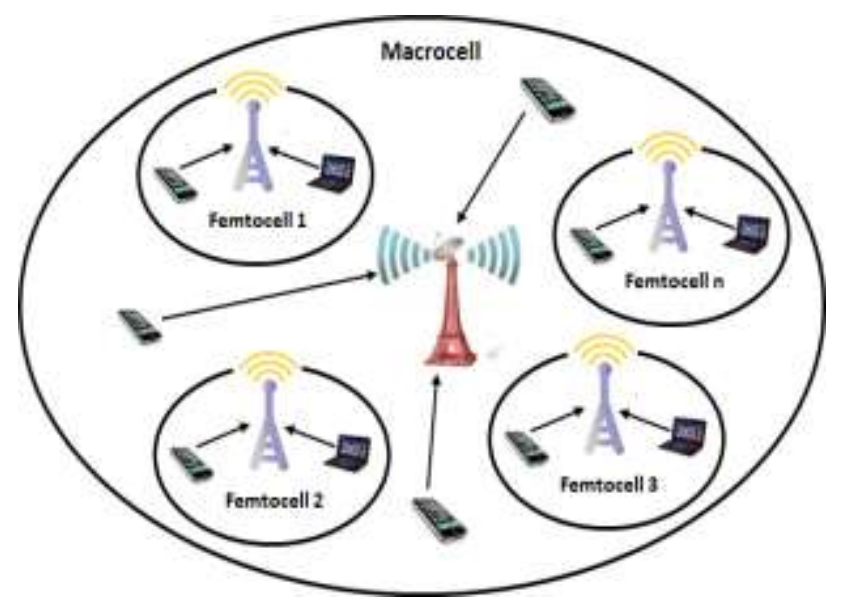

Figure 1. Two-tier macro-femtocell System Model

Received (May 13, 2018), Review Result (July 25, 2018), Accepted (July 31, 2018)

* Corresponding Author 
QoS issues relate to how handovers must be managed and carefully controlled in order to minimize dropped service due to insufficient resources available in the new cell [3-7]. Wireless resource availability varies especially frequently as users move from one access point to another. In order to deterministically guarantee QoS support for an MT, the amount of resources required to successfully perform a handover may vary arbitrarily over a wide range in mobile multimedia networks. For example, data and video applications may adapt to different service-quality levels, and consequently, may accept different levels of resources in order to ensure a successful handover [8-9]. We apply different resource control mechanisms, depending on the service class, in order to manage radio resources more efficiently [10-12]. For a low-delay, low-loss class (LL) service, throughout its entire service duration a mobile terminal can use a constant transmission rate allocated at the time of call set-up. For a low-delay, high-loss class (LH) service, the allowable minimum and maximum rates are determined at the time of call set-up. And depending on the available resources and the radio link state, the terminal controls the transmission rate between these two values. Meanwhile, for either high-delay, low-loss class (HL) or high-delay, high-loss class (HH) services, because they tolerate some delay or loss, the user does not assign the required bandwidth. Rather, the base station controls the transmission rate, depending on the network state.

In this paper, we propose a resource allocation scheme for mobile multimedia services in LTE Advanced systems. For a new call, a new resource allocation scheme is achieved by using resource reservation and load control. For a handover call, we suggest a novel resource reservation scheme to adjust the number of reserved sub-channels. Our scheme has the fundamental functions of coordinating the use of the available radio resources, and carries the maximum number of subscribers.

The remainder of this paper is organized as follows. Section 2 describes the resource management structure for our proposed system. The details of our proposed resource allocation scheme are presented in Section 3. In Section 4, performance analysis verifies the effectiveness of the proposed scheme using a computer simulation. We focus on the outage probability and total throughput. Finally, the conclusion is given in Section 5.

\section{Resource Management Structure}

We use a hybrid approach, as shown in Figure 2. Among all the radio frequencies, macrocells and femtocells have their own dedicated bands. In addition, macrocells and femtocells can share some bands. As we consider an orthogonal frequencydivision multiple access (OFDMA)-based cellular network, these bands are divided into subchannels and further divided into frames, which are shown in Figure 2 [1115]. $R_{m a}, R_{s h}$, and $R_{f e}$ denote resources dedicated to macrocells, resources shared among macrocells and femtocells, and resources dedicated to femtocells, respectively. When our system cannot accommodate user requests with $R_{f e}$ and $R_{m a}$, it allocates shared resources $R_{s h}$ to either femtocell-located users or macrocell-located users on the basis of certain criteria.

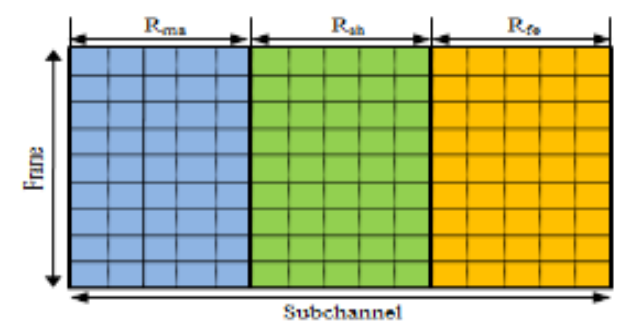

Figure 2. Resource Allocation Strategy 


\subsection{Secondary Load Control}

In order to prevent a shortage of resources in the face of handovers, our proposed scheme decreases the usage rate permitted to user services through secondary load control [14-15]. Figure 3 describes the algorithm for secondary load control in detail. That is, if the total available capacity, $\varphi_{T}$, stays lower than $T_{L o w}$ in a certain time interval, ${ }_{\left[T_{i}-T_{i+1}\right]}$, it decreases the resource usage rate of user services under execution until $\varphi_{T}$ becomes greater than or equal to the available resource threshold, $R_{T H}$. The usage rate decreases to the minimum bit rate (MiBR) in reverse order of occupation priority, that is, $\mathrm{HH}, \mathrm{HL}, \mathrm{LH}$, and LL. When overall transmission rates are rearranged, the data rate for MiBR should be guaranteed to each multimedia service at least. On the other hand, if $\varphi_{T}$ remains greater than $T_{H i g h}$ over a certain interval, this algorithm increases the resource usage rate to the maximum bit rate (MaBR) for as long as the resources left do not become less than $R_{T H}$.

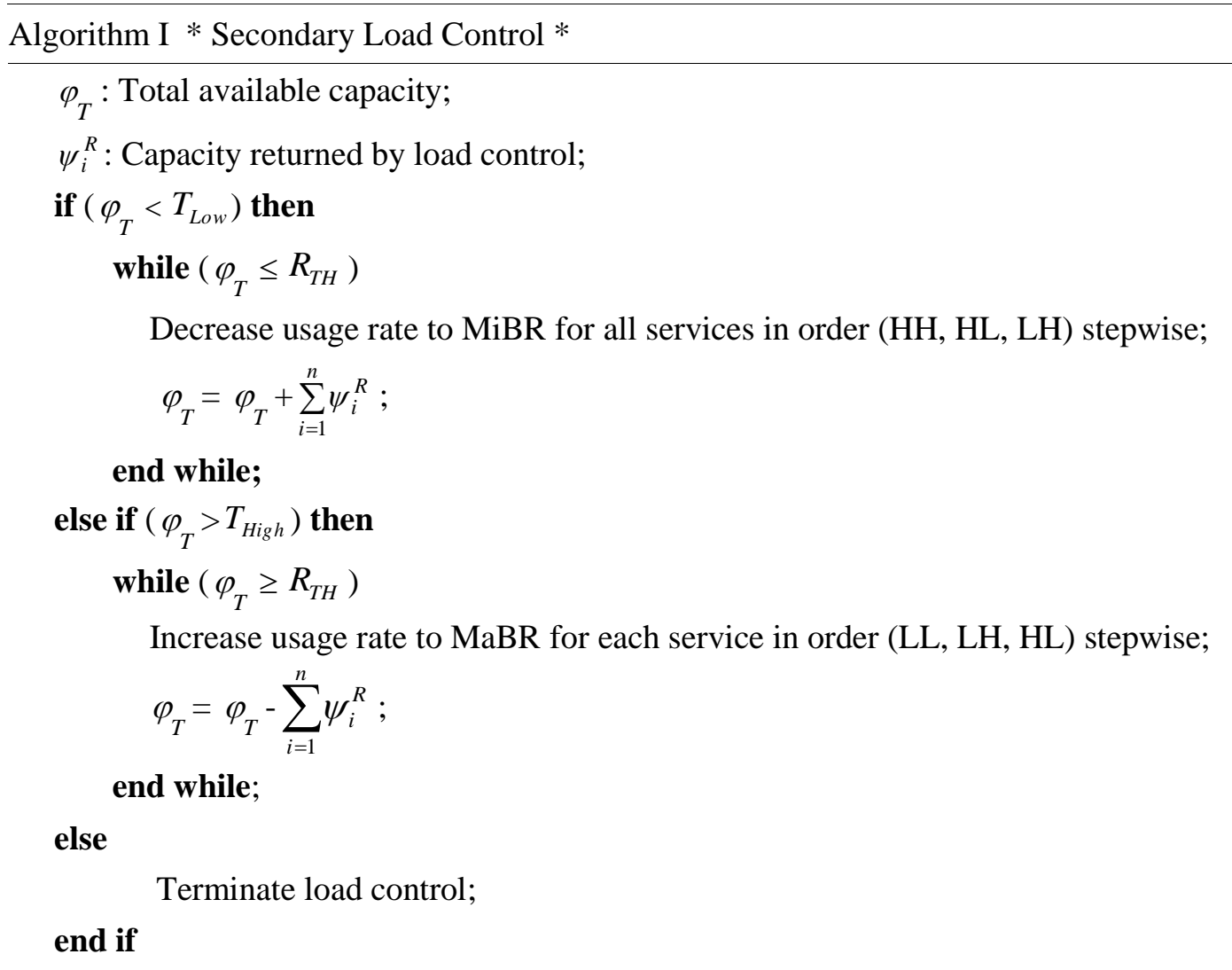

Figure 3. Secondary Load Control

\subsection{Primary Load Control}

Primary load control is executed as shown in Figure 4 if resources run out at the occurrence of a handover [14-15]. It aims to secure subchannels for handover traffic of LL or LH class services by adjusting the transmission rate of HL or HH class services. This is repeatedly executed until resources are secured amounting to MaBR or MiBR for LL or LH class services, respectively. At a minimum, resources should be guaranteed to each mobile terminal, so transient road control is done only as long as the MiBR usage rate remains for each mobile service. 


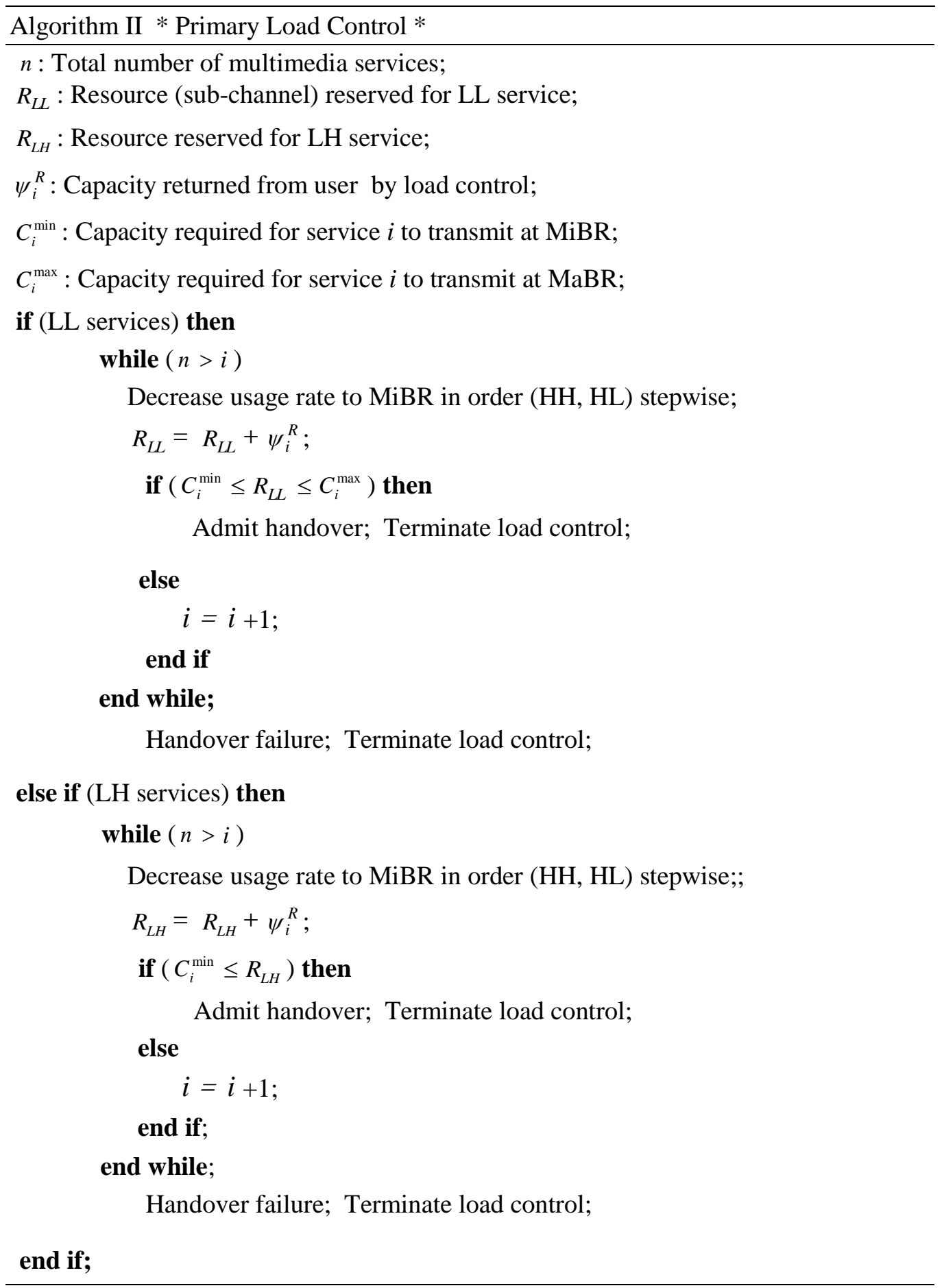

Figure 4. Primary Load Control

\section{Resource Reservation and Resource Allocation}

\subsection{Resource Reservation}

This strategy is explained in Figure 5.

(1) Step 1:

- Resource reservation need not be performed. 


\section{(2) Step 2:}

- If any resources are available in each of the cells, the resources are then reserved for each of the real-time services.

- If there are not enough resources available to accommodate a new service, a set of the reserved resources for real-time handover services can be taken up by a realtime handover service, a non-real-time handover service, and a non-real-time new service.

- If there are any resources available to support the reservation in the estimated cell, and a moving service competes with a new service for the resources, the resources are taken in the following order: a real-time handover service, a real-time new service, a non-real-time handover service, and a non-real-time new service.

- If no resources are available, the reservation is not made.

\section{(3) Step 3:}

- A set of reserved resources for real-time handover services can be taken up by a real-time handover service and a non-real-time handover service.

- If there are resources available to support the reservation in the estimated cell, and a moving service competes with a new service for the resources, the order for taking up the resources is the same as Step 2.

- If no resources are available for the reservation in $R_{m a}$ of the macrocell, the resources for $R_{f e}$ or $R_{s h}$ are reserved for a real-time service.

\section{(4) Step 4:}

- A set of the reserved resources can be taken up only by a real-time handover service.

- If a moving service competes with a new service for the available resources in the estimated cell, the resources are taken up in the following order: a real-time handover service, a non-real-time handover service, a real-time new service and a non-real-time new service.

- If no resources are available for the reservation in $R_{m a}$ of the macrocell, the resources for $R_{f e}$ or $R_{s h}$ can be reserved for real-time services.

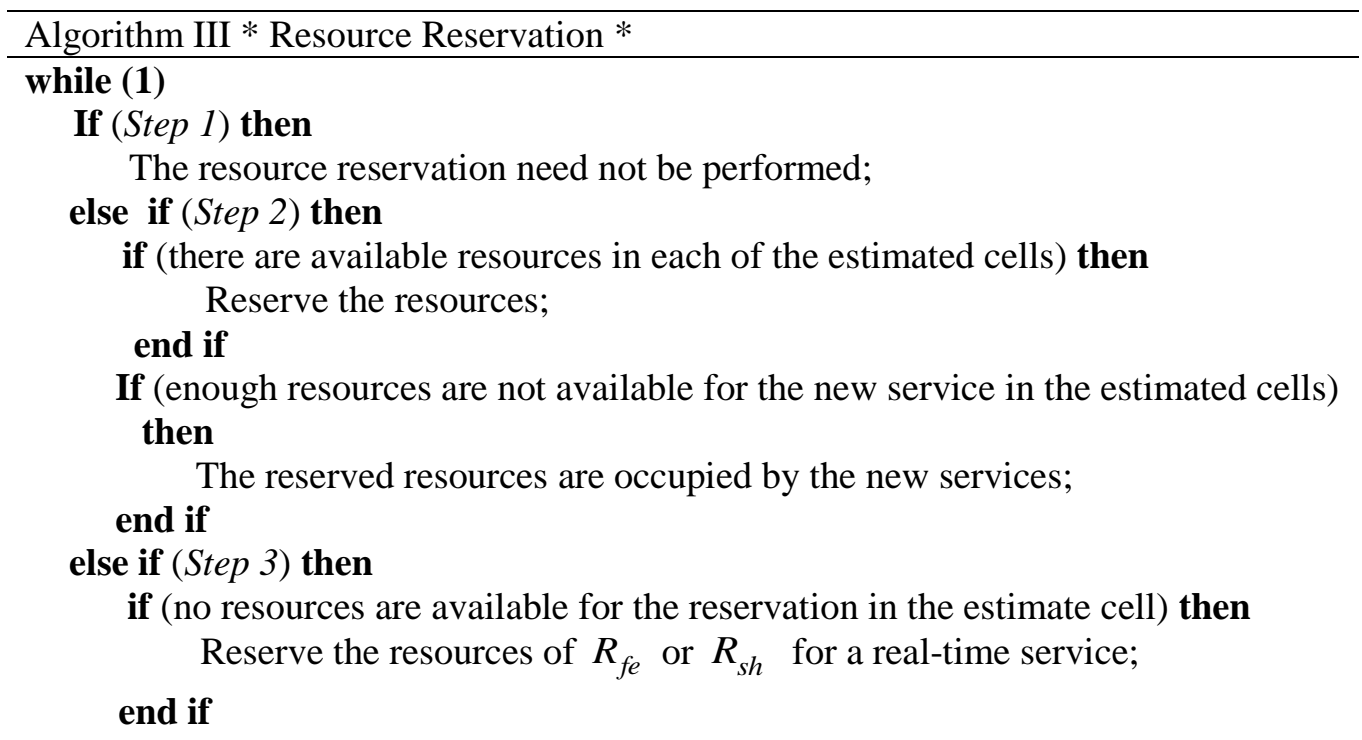


If (there are not enough resources available to accommodate the new service in the estimated cells) then

The reserved resources for real-time handover services can be taken by non-real-time new services;

end if

\section{else if (Step 4) then}

if (no resources are available for the reservation in the estimate cell) then

Reserve the resources of $R_{f e}$ or $R_{s h}$ for a real-time service;

end if

If (there are not enough resources available to accommodate the new service in the estimated cells) then

The new service cannot take the reserved resources;

end if

end if

Figure 5. Resource Reservation for Multimedia Services

\subsection{Resource Allocation Scheme for New and Handover Services}

The resource reservation is made for real-time handover services, and a set of the reserved resources can be taken up temporarily by non-real-time MTs within the target cell. On the other hand, a non-real-time MT does not make resource reservations for handovers, and its resource allocation request is buffered in the waiting queue of the target base station during handover duration time, and is given priority based on the service demand time. If the reserved set is returned because the corresponding real-time MT is handed off, the priority of the non-real-time MT that has occupied the reserved resource becomes the lowest order. This algorithm strategy is explained in Figure 6.

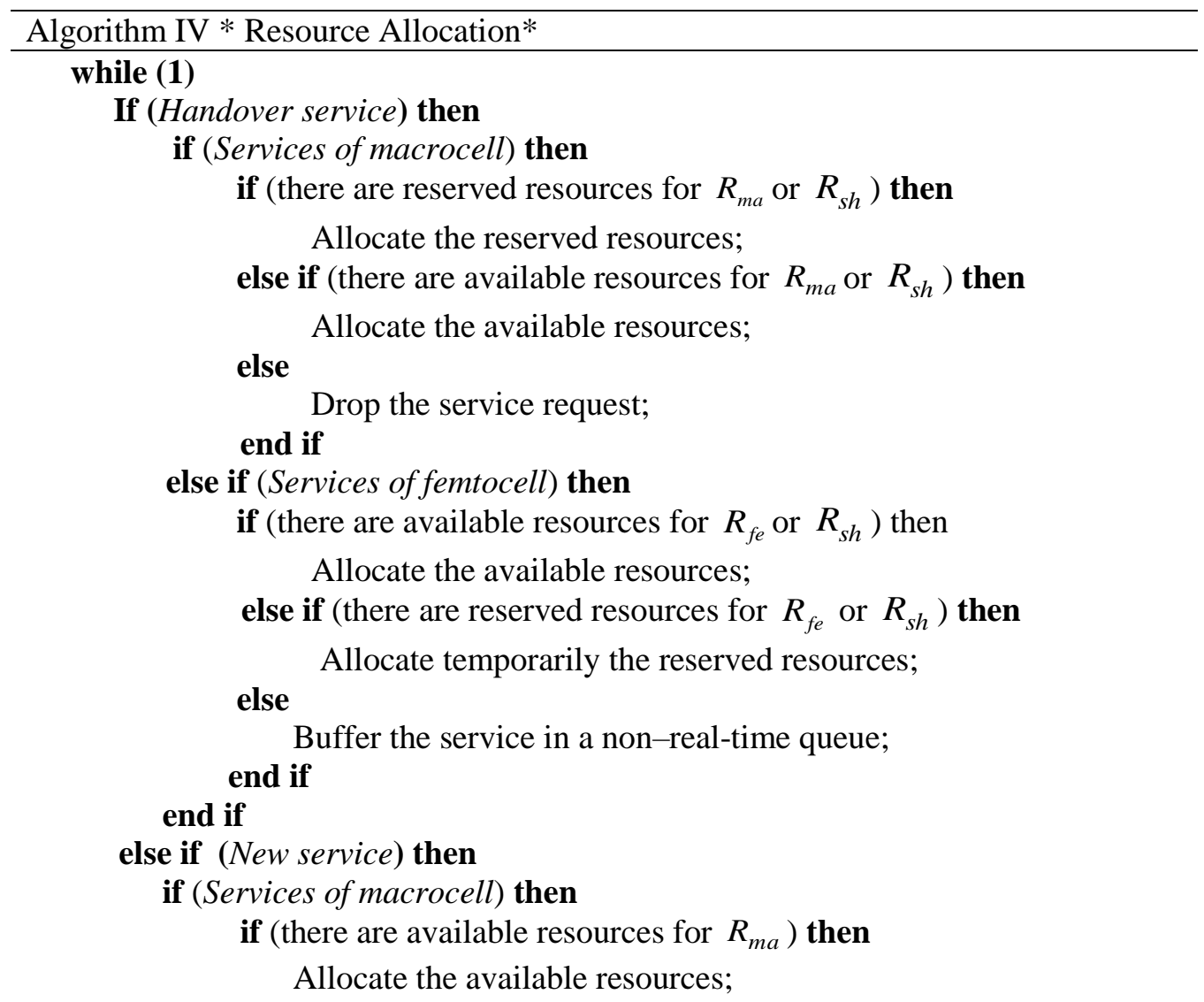




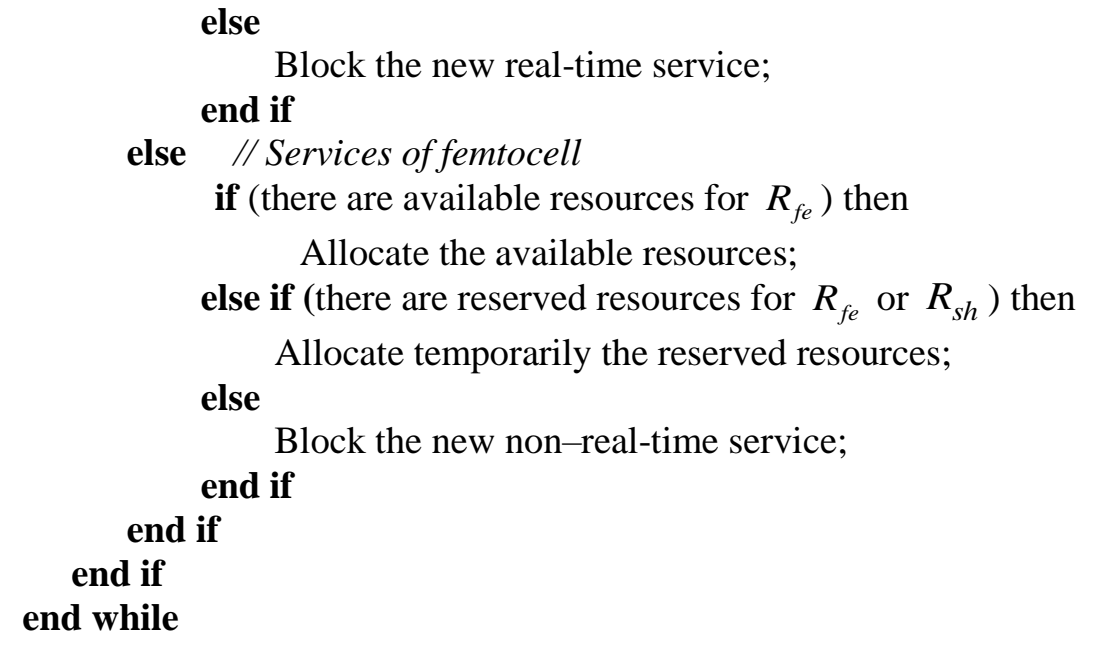

Figure 6. Resource Allocation for New and Handover Services

\section{Performance Analysis}

We refer to the 3rd Generation Partnership Project (3GPP) model in [16] for radio propagation model parameters, such as channel fading, path loss, shadowing, noise, and frequency reuse. We based the channel structure and system-level parameters on the frequency division duplex radio frame of the OFDMA-based 3GPP LTE Advanced system [17] and the 3GPP LTE Ericsson model [18, 19]. Our analysis is limited to downlink only. The major system-level simulation environments that we consider are summarized in Table 1 [20]. The transmission time interval (TTI) is assumed to be $0.5 \mathrm{~ms}$, and 20 TTIs are deployed in each frame. Seven OFDM symbols fit into the time interval corresponding to the TTI. The subcarriers are separated at $15 \mathrm{KHz}$ intervals. The minimum unit to be used for resource allocation is a resource block (RB). It has a twodimensional structure in which an RB consists of seven OFDM symbols within a TTI and 12 subcarriers each using a $15 \mathrm{KHz}$ bandwidth. Each frame comprises $600 \mathrm{RBs}$ (20 TTIs multiplied by $30 \mathrm{RBs}$ ). Every RB can be allocated to a single user, and each single user may be allocated multiple RBs based on rate requirements.

Table 1. Simulation Parameters

\begin{tabular}{|c|c|}
\hline Parameter & Value or Range \\
\hline Frequency bandwidth & $8.75 \mathrm{MHz}$ \\
\hline Number of macrocells & 19 \\
\hline Number of femtocells per macrocell & 20 \\
\hline Macrocell radius & $500 \mathrm{~m}$ \\
\hline Femtoell radius & $10 \mathrm{~m}$ \\
\hline Macrocell transmit power & $60 \mathrm{dBm}$ \\
\hline Femtocell transmit power & $20 \mathrm{dBm}$ \\
\hline Macrocell shadow shadowing & $8 \mathrm{~dB}$ \\
\hline Femtocell shadow fading & $10 \mathrm{~dB}$ \\
\hline Noise figure & $8 \mathrm{~dB}$ \\
\hline Macrocell path loss exponent & 3 \\
\hline Femtocell path loss exponent & 3.7 \\
\hline Macrocell SINR threshold & $20 \mathrm{~dB}$ \\
\hline Femtocell SINR threshold & $10 \mathrm{~dB}$ \\
\hline Modulation scheme & QPSK 3/4, 16QAM, 64QAM \\
\hline
\end{tabular}


We consider the following simulation parameters regarding received signal strength [21-22]. The mean signal attenuation by the path loss is proportional to 3.5 times the propagation distance, and the shadowing has a log-normal distribution with a standard deviation of $\sigma=6 \mathrm{~dB}$. A value for the received signal strength of less than $-16 \mathrm{~dB}$ is regarded as an error, which was therefore excluded from the calculations.

Table 2. Multimedia Services

\begin{tabular}{|c|c|c|c|c|}
\hline \multicolumn{2}{|c|}{ Service } & $\begin{array}{c}\text { Data rate } \\
\text { (Min-Max) }\end{array}$ & $\begin{array}{c}\text { Average } \\
\text { rate }\end{array}$ & $\begin{array}{c}\text { Transmission } \\
\text { delay }\end{array}$ \\
\hline \multirow{2}{*}{$\begin{array}{c}\text { Real-time } \\
\text { service }\end{array}$} & High-quality voice & $64 \mathrm{~K}$ & $32 \mathrm{~K}$ & $150 \mathrm{~ms}$ \\
\cline { 2 - 5 } & Video conference & $64 \sim 384 \mathrm{~K}$ & $256 \mathrm{~K}$ & $150 \mathrm{~ms}$ \\
\cline { 2 - 5 } & Video on demand & $3 \sim 10 \mathrm{M}$ & $5 \mathrm{M}$ & $150 \mathrm{~ms}$ \\
\hline $\begin{array}{c}\text { Non-real } \\
\text { time } \\
\text { service }\end{array}$ & World Wide Web & $256 \mathrm{~K} \sim 2 \mathrm{M}$ & $1 \mathrm{M}$ & $20 \mathrm{~s}$ \\
\cline { 2 - 5 } & Electronic commerce & $64 \mathrm{~K} \sim 384 \mathrm{~K}$ & $256 \mathrm{~K}$ & $4 \mathrm{~s}$ \\
\hline \multirow{2}{*}{2} & FTP & $1 \mathrm{M} \sim 5 \mathrm{M}$ & $3 \mathrm{M}$ & $15 \mathrm{~s}$ \\
\hline
\end{tabular}

The performance measures we considered are outage probability and total throughput. We compared our proposed resource allocation with those used by Saeed [23] and Wang [24]. Figure 7 shows the outage probabilities based on increasing the mobile multimedia service arrival rates. These results were obtained by calculating the percentage of mobile multimedia service where the mean arrival rate is less than MiBR based on all the mobile multimedia service. Our proposed scheme has much lower outage probabilities than both Saeed [23] and Wang [24]. This is attributable to the fact that the multimedia services assigned with delay priority have the highest precedence for occupying a sub-channel and are guaranteed to have a permissible MiBR.

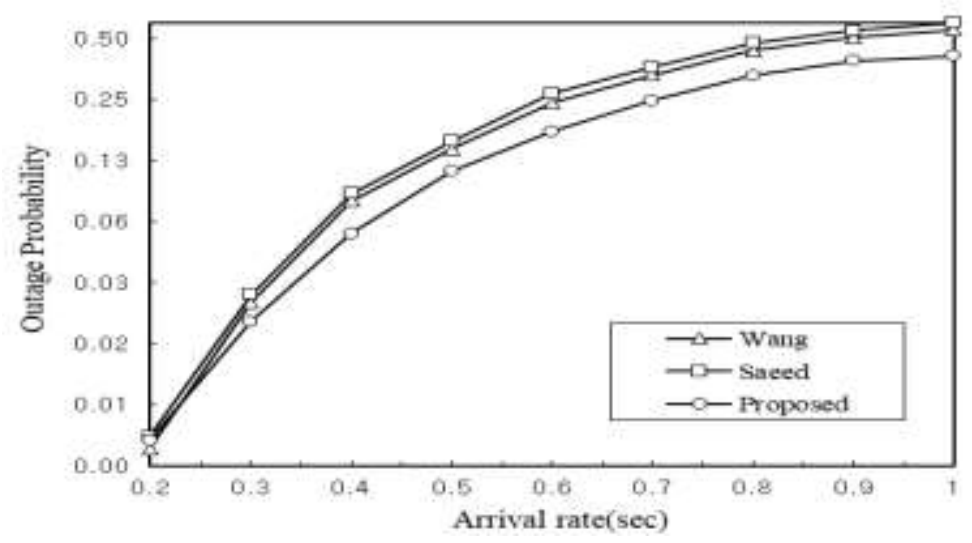

Figure 7. Comparison of Outage Probability

Figure 8 shows the variations in total throughput for the different methods when the arrival rate of new service requests increases. Results demonstrate that the total throughput of the proposed scheme decreased to about $28 \%$ and $17 \%$, compared to Saeed [23] and Wang [24], respectively. It allows overlaid-cell handovers from macrocells to femtocells for the purpose of load control. In this way, it can keep resources within the overlaid cell available at an appropriate level. Moreover, since our scheme investigates, stage by stage, the possibilities of allocation for the categorized resources in the overlaid cell, it can handle the more actively changing occupancy of resources that the increasing number of users causes. 


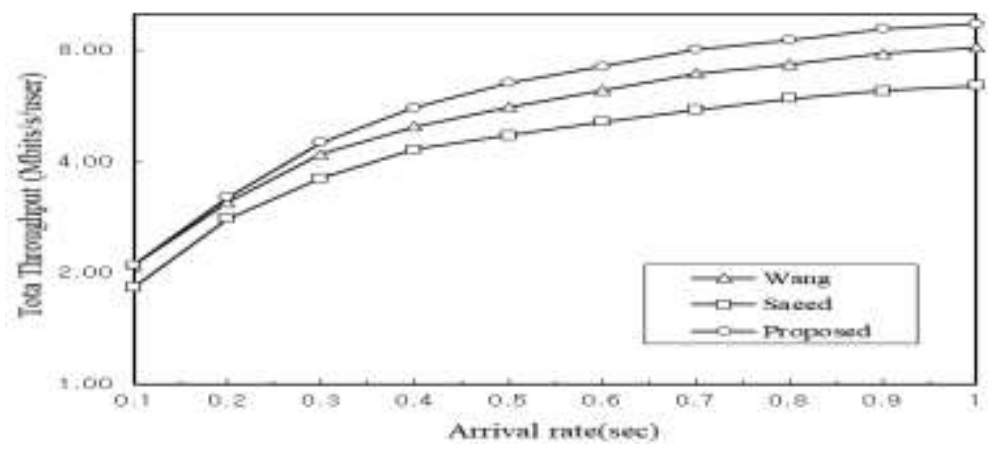

Figure 8. Comparison of Total Throughput

\section{Conclusion}

Macrocell-femtocell overlaid networks using a single terminal should be able to provide high-speed data communications services, mainly in the femtocell regions, and support the continuity of these services in any areas other than femtocell regions through coordination with legacy systems. In this paper, we proposed an adaptive resource management scheme that attempts to achieve both optimized satisfaction of user requirements and that maximizes user accommodation in macro-femto overlaid LTE Advanced networks to a certain degree. In the proposed scheme, radio resources are classified as ones having priority over new services and ones having priority over handover services, based on reservation variables. Using this, we improved the outage probability and total throughput by dynamically adjusting the amount of reserved resources according to the amount of occupied resources.

\section{Acknowledgments}

This work was supported by the Howon University Fund, 2018.

This paper is a revised and expanded version of a paper entitled 'Sub-channel Allocation for Handover in Mobile Communication System' presented at 6th International Conference on Advanced Green and Smart Technology, AGST 2018, Hanoi, Vietnam, 28-30 June 2018.

\section{References}

[1] Z. Xiao, Y. Xu, H. Feng, T. Yang, B. Hu and Y. Zhou, "Modeling Streaming QoE in Wireless Networks with Large-Scale Measurement of User Behavior", IEEE Global Communications Conference, San Diego, CA, USA, (2015) December 6-10.

[2] P. Jacob, A. S. Madhukumar and A. P. Vinod, "Cross-Polarized Complementary Frequency Allocation in Femto-Macro Networks", IEEE Vehicular Technology Conference, Glasgow, Scotland, (2015) May 11-14.

[3] A. Abdelnasser, E. Hossain and D. I. Kim, "Clustering and resource allocation for dense femtocells in a two-tier cellular OFDMA network", IEEE Transactions on Wireless Communications, vol. 13, (2014), pp. $1628-1641$.

[4] A. Saeed, E. Katranaras, M. Dianati and M. I. Imran, "Control and Data Channel Resource Allocation in Macro-femto Heterogeneous Networks", IEEE International Wireless Communications and Mobile Computing Conference, Dubrovnik, Croatia, (2015) August 24-28.

[5] S. Gayathri and R. Sabitha, "A high performance resource allocation algorithm using channel conditions in downlink of OFDMA networks", IEEE International Conference on Advanced Computing, Chennia, India, (2015) December 15-17.

[6] Z. Wang; X. Xu and R. Zhang, "Optimal Macrocell Partitioning for Redistributed Fractional Frequency Reuse in Heterogeneous Networks," IEEE Annual International Symposium on Personal, Indoor, and Mobile Radio Communications, Hong Kong, China, (2015) August 30.

[7] M. Rosdi, A Yusof, M. T. Ali, N. Ya'acob, M. Ismail, M. A. Zainali, M. S. NasroAli and B. A. Bakar, "Fairness of radio resource partitioning for macrocell and femtocell networks", IEEE Symposium on Wireless Technology and Applications, Kuching, Malaysia, (2013) September 22-25. 
[8] S. Sheikhzadeh, Na. Mokari and H. Saeedi, "Radio Resource Allocation for Interference Management in OFDMA-based Femtocell-macrocell Deployment", IEEE Iranian Conference on Electrical Engineering, Shiraz, Iran, (2016) May 10-12.

[9] R. Estrada, H. Otrok and Z. Dziong, "Clustering and Dynamic Resource Allocation for Macro-Femtocell Networks", Proceedings of IEEE 16th Inter -national Telecommunications Network Strategy and Planning Symposium, Madeira Island, Portugal, (2014) September 17-19.

[10] J. C. Lee and M. H. Lee, "Sub-channel Allocation Based on Multi-level Priority in OFDMA Systems", KSII Transactions on Internet and Information Systems, vol. 7, no. 8, (2013), pp. 1876-1889.

[11] J. Lee and M. Lee, "A QoS Provisioning Based on Load Balancing for Hand-over in OFDMA System", Journal of the Korea Society of Computer and Information, vol. 18 no. 2, (2013), pp. 59-68.

[12] J. Lee and M. Lee, "Resource Allocation Scheme for Macro-Femtocell Overlaid LTE-Advanced Networks", Korea Society of Computer Information, vol. 19, no. 12, (2014), pp. 81-89.

[13] G. Lee and J. Lee, "Resource Allocation to Support QoE in Hierarchical Macrocell-Femtocell Networks", Journal of the Korea Academia-Industrial Cooperation Society, vol. 17, no. 12, (2016), pp. 708-715.

[14] J. Lee and G. Lee, "Dynamic Frequency Allocation in OFDMA Cellular Networks", Journal of the Korea Academia-Industrial Cooperation Society, vol. 14, no. 6, (2013), pp. 2992-2998.

[15] J. Lee and J. Park, "Supporting Service Continuity in OFDMA Systems", Journal of the Korea Academia-Industrial cooperation Society, vol. 14, no. 2, (2013), pp. 850-857.

[16] 3GPP TS 36.211 v8.4.0, "Evolved Universal Terrestrial Radio Access (E-UTRA); Physical Channel and Modulation", (2008).

[17] 3GPP TR R1-050255, "Evolved Universal Terrestrial Radio Access (E-UTRA); Downlink Transmission Scheme", (2005).

[18] P. Kyosti, "WINNER II Channel Models”, IST-WINNER II D1.1.2, (2007).

[19] 3GPP TR R1-050619, "Evolved Universal Terrestrial Radio Access (E-UTRA); Downlink Radio Access", (2005).

[20] N. Fridi, S. Najeh and H. Boujemaa, "Resource Allocation in OFDMA Networks with Femto and Macro-cells Coexistence Using Fractional Frequency Reuse (FFR)", International Conference on Communications and Networking, Hammamet, Tunisia, (2014) March 19-22.

[21] J. Kim, "A Mobile-Sink based Energy-efficient Clustering Scheme in Mobile Wireless Sensor Networks", Journal of the Korea Academia-Industrial Cooperation Society, vol. 18, no. 5, (2017), pp. 19.

[22] J. Kim, "A Study on Rotation Method Appling Slip-ring of Direction Finding Antenna Mast for Mobile Radio Wave Measurement System”, Journal of the Korea Academia-Industrial Cooperation Society, vol. 18, no. 10, (2017), pp. 499-504.

[23] A. Saeed, E. Katranaras, M. Dianati and M. I. Imran, "Control and data channel resource allocation in macro-femto Heterogeneous Networks", IEEE International Wireless Communications and Mobile Computing Conference, Dubrovnik, Croatia, (2015) October 5.

[24] N. Wang, Z. Fei and J. Kuang, "QoE-Aware Resource Allocation for Mixed Traffics in Heterogeneous Networks Based on Kuhn-Munkres Algorithm", IEEE International Conference on Communication Systems (ICCS), (2016) December 14-16.

\section{Authors}

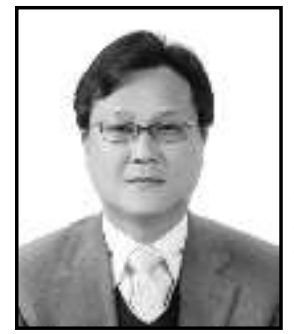

Gi-Sung Lee, he received the M.S. and Ph.D. degrees in computer science and engineering from Soongsil University, Korea, in 1996 and 2001 respectively. He has worked in the Department of Computer\&Game, Howon University. His current research interests are in the areas of Mobile Multimedia, Network Security, Database Management, Mobile Communication.

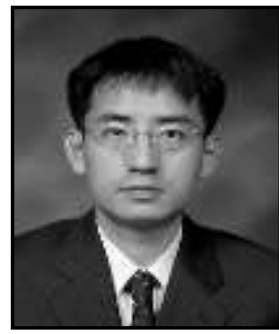

Jong-Chan Lee, he received the M.S. and Ph.D. degrees in computer science and engineering from Soongsil University, Korea, in 1996 and 2000 respectively. He as a senior member of engineering staff in ETRI from 2000 to 2005. Since 2005, he has worked in the Department of Computer Information Engineering, Kunsan National University. His current research interests are in the areas of resource management for mobile multimedia networks. 